\title{
The Challenges of an Ageing Workforce: an Introduction to the Workforce Management Issues
}

The intention of this special issue is to provide new insights into a range of the challenges facing Australia and some of our regional economic partners that have occurred due to our rapidly-ageing populations and workforces. The attraction and retention of older workers has become an imperative for governments, industry managers, unions and others, in order to maximise their contributions and enable integration as well as realise the potential of both older and younger employees in the Australian and Asian labour markets. The five papers in this volume provide some valuable insights into these challenges and suggest ways of addressing them.

Keywords: ageing workforce; HRM challenges; older worker 'problem'; workforce management

\section{INTRODUCTION}

The human population is aging at a rate "without parallel in the history of humanity" (United Nations, Department of Economic and Social Affairs, Population Division, 2001: xxviii). This phenomenon has been driven by two main factors. Firstly, increases in life expectancy and secondly, declining fertility rates - consequently, most of the developed world already has an ageing workforce (Kulik et al, 2014). The ageing of both the working and non-working population presents a number of challenges for various parties such as: policy makers, employers, employees and the wider community. How these challenges are addressed may be dependent on how transitions to a different society take place over the next few decades, "from a young settler society to an older, wealthier service oriented one." (Per Capita Australia, 2014, 7). Many policies to date have focused on trying to encourage older workers to maintain their employability and postpone retirement (Griffin and Beddie, 2011). This can be achieved through addressing workplace change and restructuring, focusing on financial systems, communities and housing to enable greater workforce and workplace participation (Per Capita Australia, 2014, 7), or officially raising the normal retirement age.

However, alarming comments on population ageing and its effects on labour markets appear regularly in the media and it is the subject of numerous national and international reports into its consequences and the associated challenges for public policy. Demographic profiles have shifted significantly, and many regional countries are now characterised by an ageing population. The United Nations (2013) Report on Population Ageing presented the salient features of this global phenomenon as involving: 
(1) an increase in the global population proportion of those aged 60 years and over from 9.2 per cent in 1990 to 21.1 per cent in 2050. This will result in a doubling of those aged 60 years and over between 2000 and 2050.

(2) population ageing that is occurring faster in emerging countries. While two thirds of the world's aged population are likely to be located in developed countries by 2050,80 per cent will be located in emerging economies.

(3) an older population that will continue to get older, with the share of those aged 80 years and older in the population increasing from 14 per cent in 2013 to 19 per cent in 2050; this will involve a three-fold increase in the proportions of this population group.

Not surprisingly, in Australia a similar demographic ageing profile is evident. The Productivity Commission (2013) and the Intergenerational Report (Federal Treasury, 2015) highlighted the following developments:

(1) The population aged 75 or more years is expected to increase from 6.4 to 14.4 per cent of the population between 2012 and 2060. In 2012, there was one person aged 100 years old or more for every 100 babies born; in 2060 the ratio is predicted to be one to four.

(2) the average life expectancy will increase; between 2054-55, life expectancy at birth is projected to be 95.1 years for men and 96.6 years for women

The ageing population, or the shifting demographic profile forecast for Australia, is about the average found across the globe. There are also other nations where the population is ageing and the proportion of older persons is projected to be much greater than in Australia. These countries include Japan, Korea, Portugal, Greece, Italy and Spain (OECD, 2006).

Discussion of population ageing in general emphasises the challenges and potential adverse consequences for the community: the increase in the dependency ratio (the decline in the ratio of the workforce to the population); the community costs of health and aged care; the increase in the costs of age pensions and public support to the aged, such as concessional health and transport costs; and increases in health and mobility/disability problems linked to ageing. Ageing will also bring potential fiscal challenges. As the Intergenerational Report (Federal Treasury 2015, xvi) states: 
Over the next 40 years, Australian governments will face increasing fiscal pressures as the population grows and ages. The report considers the anticipated patterns of spending across the programs most affected by demographic factors: health expenditure, Age and Service Pensions and aged care funding. Based on 'previous policy', the ratio of payments to GDP would have been on track to reach 37.0 per cent in 2054-55. This would be dramatically higher than the historic high of 27.6 per cent in 1984-85. If left unchecked, this would mean drastic future cuts to payments, higher taxes, or both. Australian Government real health expenditure per person is projected to more than double over the next 40 years.

Population ageing is not, however, all about hardship and impossible fiscal challenges. The changing population profile will generate demand for a different mix of commodities associated with healthcare, leisure, financial services and hospitality. Not all older Australians will be dependent on social services and the aged pension; some retiring baby boomers have accumulated superannuation savings to finance their retirement and they have high levels of home ownership in cities where house prices have considerably increased over the past decades. For example, the United Nations (2013, xii) noted that older age cohorts contribute to intergenerational income transfers:

Older persons can increasingly live independently (alone or with their spouse only), and in most countries, they support themselves financially with their own labour earnings, income from their assets, and through public transfers. In most countries with pertinent data, older persons make net financial contributions to younger family members until rather advanced ages.

The Australian Human Rights Commission (2013) noted that those aged between 55 and 74 years possess the fastest growing household wealth of any age cohort, and hold the largest share of national wealth. This situation generates demands for services and business opportunities; the Per Capita $(2014,15)$ report on ageing, for example, commented that:

The generation that is now retiring - the baby boomers-have higher expectations, different lifestyle choices and different consumption patterns than their forebears, creating new needs for business to meet. Many things generally out of reach to older Australians in past decades, like travel, clothing, entertainment, dining out and home redecoration just to name some, are now in greater demand, making older consumers a market segment crying out for entrepreneurial attention. The possibilities are almost endless, with baby boomers presenting a vast market for a potential explosion of products and services-new dating websites, longevity insurance and new kinds of food amongst others.

With an ageing population there exists a parallel ageing workforce and the workforce profile will shift in line with the population profile. More older Australians will be employed as a result of a combination of pressures, including lifting the entitlement age for the aged pension; the abolition of forced retirement ages through anti-discrimination legislation; policy developments such as supporting access to retirement incomes while in employment; the demand for skilled and 
experienced workers; the availability of flexible employment arrangements (part-time, short term); and the improvement in general health standards of the older population (Per Capita, 2014). The labour force participation rate for older workers will increase, with the Federal Treasury (2015) suggesting that the labour force participation rate of those aged over 65 years will increase from 12.9 per cent in 2014 to 17.3 per cent in 2054 . Within the 60-64 age group the employment to population ratio increased from 32 per cent in 2000 to 54 per cent in 2014 (Per Capita, 2014). While population ageing would suggest a decline in labour force participation rates and an increase in the dependency ratio (Federal Treasury, 2015), relative to other OECD economies Australia has to date had low participation rates for women and older age groups (Waterhouse and Burgess, 2010). Both groups can be expected to increase their participation rates and their share of the workforce in the future and in the process partially offset the anticipated decline in the average labour force participation rate that will follow from population ageing.

With an ageing workforce there is a challenge for human resource management (HRM) and managers with regard to the "older worker problem". The nature of the problem is in fact, a series of problems that are represented as associated with older workers. It is alleged that they bring with them a range of attitudes, character traits and human capital deficiencies that make their hiring problematic (Taylor, 2011). They are often perceived as reluctant to learn new skills and unfamiliar with information technologies; they do not engage with social media, they do not accept authority, they do not have the energy or the physical capabilities to handle the job, they cannot effectively work with younger workers (especially managers) or in teams, they lack ambition and drive and they are reluctant to work long hours. Other research indicates that older workers are treated less favourably than younger ones in the provision of training (Warr and Birdi, 1998). In short, older workers can be considered 'bad news' and best avoided. These alleged negativities concerning older workers form part of the ageist stereotyping that is widespread in Australia and elsewhere in the region. The Australian Human Rights Commission (2013, 4-5) published survey findings that indicated that:

$71 \%$ of all Australians feel that age discrimination in Australia is common. Most community and business respondents feel that age discrimination is likely to occur in: the workplace (88\% community respondents, $92 \%$ business respondents), retail situations (60\% business and $60 \%$ community) and social situations (56\% business and 57\% community).35\% of Australians aged 55-64 years and 43\% of Australians aged 65+ years have experienced discrimination because of their age. The most common types of age-related discrimination, experienced by over $50 \%$ of older Australians, are: being turned down from a position (67\% of Australians aged 54-65; $50 \%$ aged 65+); being ignored (59\% of Australians aged 54-65; 66\% aged 65+); being treated with disrespect (51\% of Australians aged 54-65; 64\% aged 65+); being subjected to jokes about ageing (53\% of Australians aged 54-65; 53\% aged 65+). 
There is evidence of systemic discrimination and barriers being present in hiring decisions and in workplace facilities. The Australian Human Rights Commission (2013) listed a series of barriers to the employment of older workers that included discrimination in hiring and firing on the basis of age, a lack of flexible employment arrangements, and an absence of workplace facilities suitable for older workers. In addition, complex and changing laws around access to aged pensions and superannuation entitlements act as a barrier to workforce participation.

There are of course advantages and significant potential for businesses in hiring and retaining older workers. The first is that population ageing will place pressure on the supply of skilled labour; as a matter of competitive necessity, businesses will need to attract and retain older workers. Also, with population ageing there will be a demand for increased and different services, ranging from clothing through to leisure and hospitality; the nature of market demand will change, and one way of meeting that demand is to have workers who can identify with customers (Per Capita, 2014). Older workers have also been found to possess characteristics that (compared to younger age groups) make them attractive as employees. These features may include experience, skills, leadership, lower absenteeism, higher commitment, professional knowledge and reliability (AHRI, 2015).

Some older workers report workplace problems that discourage and reduce their retention and participation. For example, Eurofound (2012) reported that, on average, older workers have reduced access to training and development programs as compared to younger workers; in general they tend to feel anxious and insecure about their future employment prospects; health and illness issues are prevalent for older workers in jobs that are physically demanding and many older workers would prefer to work fewer hours.

Thus the HRM challenges linked to an ageing workforce are considerable. Older Australians at Work (2014) suggests that organisations will have to be innovative and accommodating to support an ageing workforce through such activities as improved workplace health and safety monitoring, enhancing knowledge transfer between generations in the organisation, facilitating inter-generational teamwork and ensuring access to training and skill development across the organisation. Major challenges identified in this volume include the following. First, and reiterating elements of the preceding discussion, ageist attitudes and stereotyping need to be addressed. An ageing workforce is inevitable and organisations will have to accommodate and support older workers now and in the future by addressing issues associated with the attraction and retention of older workers. Second, older workers bring many potential advantages to an organisation, especially in terms of experience, professional 
and institutional knowledge, commitment and reliability - the challenges concern how to encourage employers, managers and co-workers to recognise and capitalise on these advantages. Third, older workers have different demands and expectations with regard to career development, working time arrangements and workplace facilities. Older workers generally do not want to work long hours and for many, part-time hours are attractive; additionally many older workers often have dual caring responsibilities for both parents and grandchildren, so work and family balance is also important (Waterhouse and Burgess, 2010). Fourth, the demographic profile of workforces will be stretched. Human resource managers will have to consider how to manage a diverse inter-generational workforce where expectations, work arrangements, career expectations, skill and experience profiles are very different. Fifth, line managers will need to be increasingly sensitive to the needs and potential contribution of older workers to the organisation (AHRI, 2015). There is also a need to consider the impact of an aging population on younger workers. While there is a need to attract and retain older workers, such strategies may block the promotion and advancement of younger workers (Kulik et al, 2014). These and other challenges are discussed in the articles included in this volume which is organised as follows.

\section{The organisation of the volume}

By 2050 it has been estimated that one in three Chinese will be over 60 years of age, thus creating a population of older people that is larger than the entire population of the United States (Chatterjee, Nankervis and Connell, 2014). Sharply declining fertility rates and increases in life expectancy have resulted in a number of challenges associated with China's aging population that are addressed in the first paper in this volume "Interesting times" - The challenges of China's demographic deficit, by Nankervis and Prikshat. The authors maintain that the positive aspects of China's growth have obscured demographic and labour market characteristics which threaten its future prosperity. They identify four key factors which are currently influencing labour market effectiveness. These factors are - a rapidly ageing workforce, declining fertility levels, the adverse impacts of the one-child policy, and a flawed education system. The article delineates the implications of these challenges, analyses their antecedents and consequences, then provides a series of remedial recommendations for government, industry and future researchers.

The second article moves on to the challenges of the ageing workforce within the Australian context, where Gekara, Snell and Chhetri ask whether older workers are 'crowding out' the young. The authors explore a paradox in the Australian labour market whereby ageing workforces and significant 
skills shortages in certain sectors are juxtaposed with rising youth unemployment. Munnell and Wu (2013) also asked a similar question - Do older workers squeeze out younger workers? - comparing findings across the United States (U.S) and China. They pointed out that in China a major reason for resisting higher statutory retirement ages has been concern about the impact on younger workers. However, they found no evidence that increasing the employment of older persons reduces the job opportunities of younger people, either in the U.S or in China. Moreover, Munnell and Wu (2013) reported that the patterns were consistent for both men and women, as well as for groups with different levels of education.

Gekara, Snell and Chhetri focus on a particular sector in Australia - the logistics and transport industry - as the research context, to analyse whether young workers are being 'crowded out' by their older colleagues who are delaying retirement. Their study found that the supply of older workers was not the major barrier for youth access to employment, instead the authors found that it was employers' recruitment practices and strategies related to the cost of training younger workers.

The next paper in this volume considers multi-generational issues. In particular, Holian considers the three generations found in most workplaces and the challenges associated with to their career development and management in relation to their life-stages. She argues that, although much research has been conducted to explore ways in which younger generations may need to be managed differently to 'baby boomers', most recommendations have concentrated on ways in which older managers can better understand younger workers. Conversely, she points out that there is a growing need for younger managers to develop strategies and skills that will assist with the management of older workers - a topic that is explored in detail in this article. Her conclusions include recommendations for the attraction and retention of workers across the generations.

The fourth paper moves to the aged care sector, where Radford, Shacklock and Meissner examine factors influencing older (50 years plus) personal care workers' (PCWs') intentions to remain working within four aged care facilities. Reporting on quantitative and qualitative findings from a crosssectional survey, findings showed that both personal (age, location of the job, health and family commitments) and organisational (job satisfaction, perceived supervisor support, job embeddedness, working environment, pay, career opportunities, and job stability) factors influenced retention, although the organisational factors prevailed over personal factors, indicating important implications for aged care employers. 
The final paper in the volume also focuses on personal care workers and the aged care sector. While Montague, Burgess and Connell concentrate on the attraction and retention of Australia's aged care workers, they do so with the intention of developing both policy and organisational responses. The authors highlight the imminent challenges related to increased demands on the residential aged care workforce from Australia's ageing population. Moreover, they point out that personal care workers are reportedly older than the average age of workers in other fields, so the ageing workers are in turn caring for what might be only a slightly older ageing population. Specifically, the study focuses on both policy and human resource management changes recommended for the residential aged care sector in order to attract and retain Australia's ageing aged care workforce both now and in the future.

The papers included in this special issue provide new insights into the similar (and disparate) features of the challenges facing Australia and many, if not most, of our regional economic partners, due to rapidly-ageing populations and associated workforces. Common themes include the complexity and interconnectedness of these challenges; potential conflicts between different stakeholders; and the demand for effective and integrated approaches by governments, employers and unions. The papers included here explore a range of pertinent factors - broadly, and within several different industry sectors; including multiple social and demographic aberrations in the Chinese labour market as a whole; the impact of multi-generational workforces in Australian workplaces generally, and more specifically in the logistics and transport sector; and the particular concerns faced by employers of personal care workers with respect to problems related to their future staffing strategies.

Some of the challenges of managing an ageing workforce are predicated on organisational system revisions, whilst others are primarily associated with attention to the personal concerns of older and younger employees and their inter-relationships. All, however, will demand strategic and effective interventions by national governments, industry managers, unions, communities and others, in order to both maximise the contributions and to realise the potential of older and younger employees in the Australian and Asian labour markets. Failure to do so is likely to result in significant adverse social, economic (and ultimately political), effects for stakeholders. 
The specific implications for governments include more creative labour market planning; innovative policies designed to retain older employees and to attract and motivate younger workers; and reconsideration of the revision of retirement and superannuation programs. For employers and their human resource professionals, they include new attraction and retention techniques, and more balanced motivational and development programs for both employee groups. Future researchers might focus on more comprehensive surveys to identify the challenges of the ageing workforce across the Asian region; case studies which illustrate the particular difficulties faced in specific industry sectors and/or Asian countries; and reports which can provide guidance to governments and relevant industry sectors in undertaking actions to address a challenge that is not going to disappear.

\section{Acknowledgements}

The editors of the special issue acknowledge the support and encouragement of the journal editors. We also thank the referees who improved the quality of the papers. Finally, the support of the School of Management, Curtin University, in funding a research workshop on this topic assisted in bringing together many of the authors and papers in this collection.

\section{References}

Australian Human Rights Commission (2013), Fact or Fiction. Stereotypes of Older Australians. Canberra.

Chatterjee, S., Nankervis, A., \& Connell, J. (2014). Framing the Emerging Talent Crisis in India and China a Human Capital Perspective. South Asian Journal of Human Resources Management, $1(1), 25-43$.

AHRI (2015), Pulse Survey: Older Workers. Melbourne

Eurofound (2012), Sustainable work and the ageing workforce, Publications Office of the European Union, Luxembourg

Federal Treasury (2015), Intergenerational Report 2015. Canberra.

Kulik, C. T., Ryan, S., Harper, S., \& George, G. (2014). Aging populations and management. Academy of Management Journal, 57(4), 929-935.

Griffin, T., \& Beddie, F. (2011). Older Workers: Research Readings. National Centre for Vocational Education Research Ltd. „, Australia.

Munnell, A., \& Wu, A. (2013). Do older workers squeeze out younger workers? Stanford Institute for Economic Policy Research Discussion Paper, (13-011). 
OECD (2006), Live Longer, Work Longer, OECD, Paris.

Older Australians at Work Thought Summit (2014), xxx

Per Capita Australia (2014), Blueprint for an Ageing Australia. Sydney.

Productivity Commission (2005), Economic Implications of an Ageing Australia, Research Report, Canberra.

Productivity Commission (2013), An Ageing Australia: Preparing for the Future. Melbourne.

Taylor, P. (2011). Ageism and age discrimination in the labour market and employer responses in Griffin, T., \& Beddie, F. (Eds) Older Workers: Research Readings. 46-63. National Centre for Vocational Education Research Ltd. PO Box 8288, Stational Arcade, Adelaide, SA 5000, Australia

United Nations, Department of Economic and Social Affairs, Population Division. 2001. World population ageing 1950-2050. Available at: http://www.un.org /esa/population/publications/worldageing19502050/.

United Nations (2013), World Population Ageing 2013. Department of Economic and Social Affairs Population Division. New York.

Warr, P \& Birdi, K (1998), 'Employee age and voluntary development activity', International Journal ofTraining and Development, vol.2, no.3, pp.190-204.

Waterhouse, J. and Burgess, J. (2010) An Ageing Workforce: HRM Challenges. in J. Connell \& S. Teo (eds.), Strategic HRM: Contemporary Issues in the Asia Pacific Region, Tilde Press, Melbourne, pp. 233-255 